\title{
Comparison of open appendectomy and laparoscopic appendectomy with laparoscopic intracorporeal knotting and glove endobag techniques: A prospective observational study
}

Mehmet Aziret ${ }^{1}$, Süleyman Çetinkünar² ${ }^{2}$, Hasan Erdem², Șahin Kahramanca ${ }^{3}$, Hilmi Bozkurt² ${ }^{2}$ Onur Dülgeroğlư ${ }^{3}$, Ali Cihat Yıldırım³, Oktay İrkörücü², Emre Birzad Gölboyu ${ }^{4}$

\section{ABSTRACT}

Cite this paper as: Aziret $M$, Çetinkünar $S$, Erdem H, Kahramanca Ş, Bozkurt H, Dülgeroğlu 0, et al. Comparison of open appendectomy and laparoscopic appendectomy with laparoscopic intracorporea knotting and glove endobag techniques: A prospective observational study. Turk J Surg 2017; 33: 258-266.

'Department of General Surgery, Sakarya Univesity School of Medicine, Sakarya, Turkey ${ }^{2}$ Department of General Surgery, Adana Numune Training and Research Hospital, Adana, Turkey ${ }^{3}$ Department of General Surgery, Kars State Hospital, Kars, Turkey ${ }^{4}$ Department of Anesthesiology and Reanimation, Kars State Hospital, Kars, Turkey

This study was presented at the $12^{\text {th }}$ National Congress of Endoscopic and Laparoscopic Surgery 22-26 April 2015, Antalya, Turkey.

\section{Address for Correspondence} Mehmet Aziret

e-mail:mhmtaziret@gmail.com

Received: 16.04 .2016 Accepted: 26.09.2016

\section{oCopyright 2017} by Turkish Surgical Association
Objective: Despite the recent increase in the use of laparoscopic appendectomy procedures to treat acute appendicitis, laparoscopic appendectomy is not necessarily the best treatment modality. The aim of this study is to examine the value of laparoscopic intracorporeal knotting and glove endobag in terms of various parameters and in terms of reducing the costs related to laparoscopic appendectomy procedures.

Material and Methods: Seventy-two acute appendicitis patients who underwent laparoscopic appendectomy and open appendectomy surgery were enrolled in the study and were evaluated prospectively. The patients were divided into two groups: group 1 was treated with laparoscopic appendectomy using laparoscopic intracorpreal knotting and glove endobag ( $n=36)$ and group 2 was treated with open appendectomy $(n=36)$. The two groups were statistically compared in terms of preoperative symptoms and signs, laboratory and imaging findings, operation time and technique, pain score, gas and stool outputs, duration of hospital stay, return to normal activity, and complications. Results: No statistically significant differences were found between the groups in relation to gender, age, body mass index, or pre-operation findings, which included loss of appetite, vomiting, time when pain started, displacement of pain, defense, rebound, imaging methods, and laboratory and pathology examinations ( $p>0.05)$. Moreover, there were no differences between the groups with respect to drain usage, hospital stay time, or complications ( $p>0.05)$. In contrast, a statistically significant difference was found between the groups in terms of operation time, pain scores, gas-stool outputs, and return to normal activity in the laparoscopic appendectomy group $(p=0.001)$.

Conclusion: Laparoscopic appendectomy can be performed in a facile, safe, and cost-effective manner with laparoscopic intracorporeal knotting and glove endobag. By using these techniques, the use of expensive instruments can be avoided when performing laparoscopic appendectomy.

Keywords: Acute appendicitis, laparoscopic appendectomy, laparoscopic intracorporeal knotting, glove endobag

\section{INTRODUCTION}

Acute appendicitis is one of the most common causes of acute abdomen in all ages. It occurs more frequently in men than in women (male/female: 1.3/1); the mean and median ages related to this pathology are 31.3 and 22 years, respectively (1-3). Open appendectomy (OA), which was first described by McBurney (4) in 1894, is the most frequently performed emergency abdominal operation in the world. However, the use of the laparoscopic appendectomy (LA) procedure has rapidly increased since it was first described by Semm in 1984 (5). Although LA is commonly performed for acute appendicitis, it is not always the best treatment choice. Many studies comparing LA and OA with respect to treatment and follow-up have been conducted. These studies have reported less postoperative surgical-site infection, decreased need for analgesics, much greater visualization, rapid healing, shorter hospital stay times, and earlier return to normal activity (RTNA) rates associated with LA (6-10). However, because of the high costs related to endostaplers, endoclips, and knottings, LA is not the most efficient operation technique $(11,12)$.

Our aim in this study is to prospectively compare OA and LA performed with laparoscopic intracorporeal knotting and glove endobag; we also wish to demonstrate that the latter is a facile and effective alternative LA procedure.

\section{MATERIAL AND METHODS}

\section{Methodology and Ethics}

This study was conducted in the Surgery Department at Kars Harakani State Hospital during the period from May 2014 to April 2015. A total of 72 patients who were treated for acute appendicitis were eligible for the study. These 72 patients were divided into two groups: the LA group (group 1) $(n=36)$ and the OA group (group 2$)(n=36)$. All the patients were evaluated in terms of age; gender; perioperative symptoms 
and signs, such as physical examination results and laboratory and imaging findings; operation time and technique; postoperative pain scores determined by the visual analog scale (VAS); gas-stool outputs; hospital stay time; postoperative complications; and RTNA. The diagnosis of acute appendicitis was made on the basis of physical examination and laboratory and imaging findings (Figure 1). The patients who were diagnosed with acute appendicitis were operated on within 12 hours. Consent forms were obtained from the patients. Approval for the study protocol was obtained from the Ethical Committee of our center.

\section{Inclusion Criteria}

Patients who were willing to provide written informed consent, were between the ages of 17 and 65 years, had an international normalizing ratio (INR) $<1.5$, a prothrombin time (PT) $<15$ seconds, partial thromboplastin (APTT) in the normal range, and platelet counts $>50,000 / \mathrm{mm}^{3}$, and showed clinical suspicion of acute appendicitis (defense, rebound), with supporting appendicitis findings, such as those taken from imaging and laboratory results, were included in the study.

\section{Exclusion Criteria}

Patients who were not willing to provide informed consent, were younger than 16 or older than 65 years of age, and had

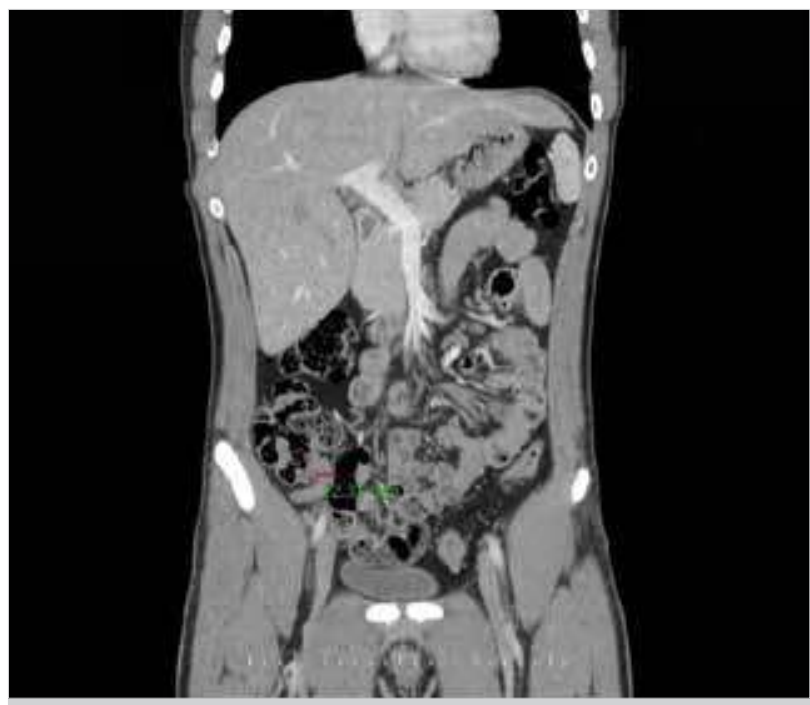

Figure 1. Acute appendicitis with computed tomography

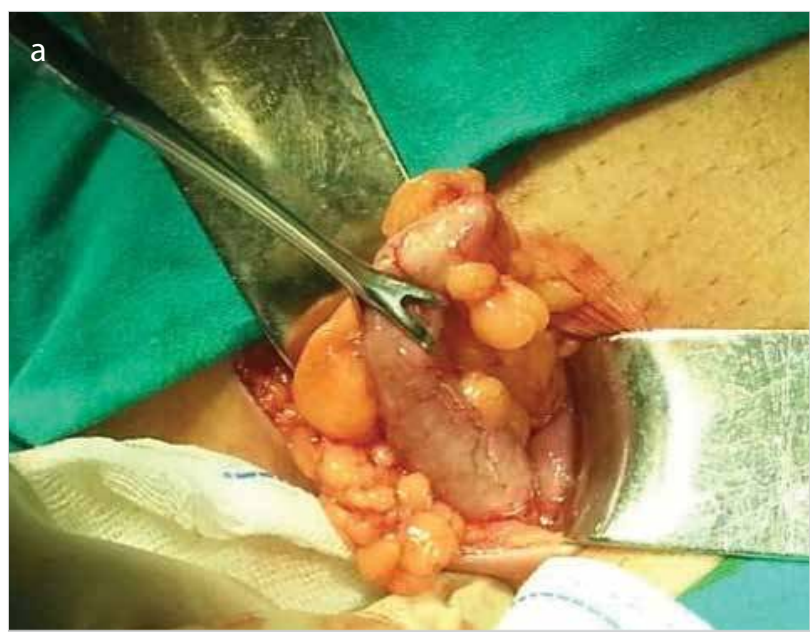

abnormal hemodynamic parameters, perforated appendicitis, ovarian cyst rupture, tub ovarian abscess, multiple organ failure, congestive heart failure, chronic obstructive pulmonary disease, systemic connective tissue diseases, or rheumatism were excluded from the study.

\section{Surgical Procedure}

All the patients were administered first-generation cephalosporin for antibiotic prophylaxis, while some patients also received second-generation cephalosporin and metronidazole. The operation time was defined as the time of induction of anesthesia to the point of extubation. All operations were performed by two surgeons. Following the operation, an intramuscular injection of $75 \mathrm{mg}$ of diclofenac sodium was administered to the patients and continued at 8 hour-intervals. Every patient began receiving liquid foods 6-8 hours after the operation.

\section{Open Appendectomy}

To access the appendix, McBurney's incision was used on all patients. The appendix was located after entering the abdominal cavity. First, the mesoappendix was divided with $3 / 0$ silk knots, and the base of the appendix was then ligated with $2 / 0$ silk before the appendectomy specimen was removed from the abdominal cavity (Figure 2a). The appendix stump was not buried in any of the patients. A drain was placed in patients with gangrenous appendicitis and to control hemostasis.

\section{Laparoscopic Appendectomy}

The North American three-port technique was used on all patients. Prior to inserting the trocar, a Foley catheter was inserted into the bladder. A $10 \mathrm{~mm}$ trocar was then inserted under the umbilicus using the open technique. Pneumoperitoneum was applied with carbon dioxide $\left(\mathrm{CO}_{2}\right)$, and intraabdominal pressure was fixed at $10-12 \mathrm{mmHg}$. Next, a $5 \mathrm{~mm}$ trocar was inserted into the suprapubic area before applying a $10 \mathrm{~mm}$ trocar to the left iliac fossa under direct vision (Figure 2b). The possibility of hemorrhaging or organ injury occurring in connection with the trocar was controlled prior to performing the appendectomy. After the appendix became visible, it was lifted from the mesoappendix. A $10 \mathrm{~mm}$ bipolar vessel sealer (LigaSure; Valleylabs, Tyco, USA) was used for the mesoappendix dissection. Once the base of the appendix was revealed, it was ligated with $2 / 0$ silk $(10-12 \mathrm{~cm})$ using the intracorporeal knotting technique (Figure 3 ). The appendectomy specimen

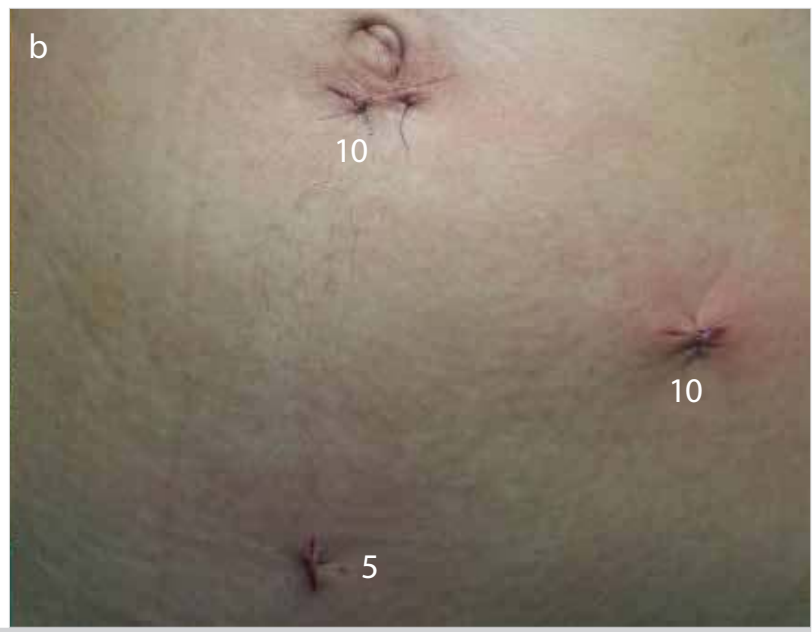

Figure 2. a, b. Intraoperative open appendectomy (a), Laparoscopic appendectomy trocar sites (b) 


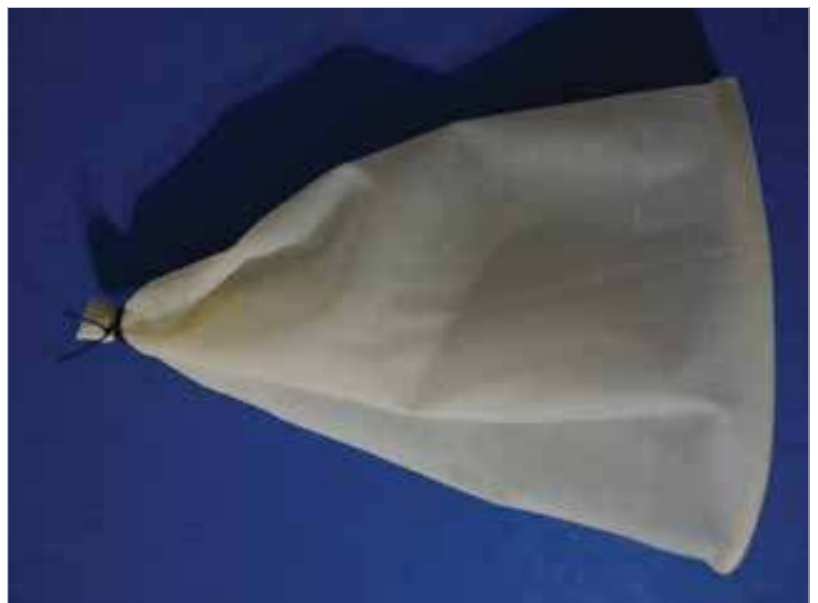

Figure 3. Preparation of the glove endobag

was then removed with a $10 \mathrm{~mm}$ trocar using a sterile glove endobag. In one patient who had suppurate appendicitis, the appendectomy area was washed with physiological serum ( $0.9 \%$ sodium chloride) and then aspirated. Irrigation was not performed for any other patients. A drain was only used in patients with gangrenous appendicitis and to control hemostasis.

\section{Preparation of Glove Endobag and Removal of Specimen} A number 7 wrist-size sterile glove was cut to approximately $7-9 \mathrm{~cm}$; then, the glove was ligated $0.5 \mathrm{~cm}$ from the distal with $2 / 0$ silk. The sterile glove endobag was washed with physiological serum and inserted into the abdominal cavity using a $10 \mathrm{~mm}$ trocar in the left iliac fossa. The appendectomy specimen was removed with a $10 \mathrm{~mm}$ trocar using the glove endobag (Figure 4). No other endobag instruments were used on any patients in our study.

\section{Anesthesia Protocol}

Before the patients entered the operation room, they were administered $2 \mathrm{mg}$ of midazolam. The patients were monitored, with control measures taken for heart rate and rhythm, noninvasive arterial blood pressure, peripheral arterial oxygen saturation $\left(\mathrm{SpO}_{2}\right)$, and end-tidal $\mathrm{CO}_{2}\left(\mathrm{EtCO}_{2}\right)$. To induce anesthesia, $2-2.5 \mathrm{mg} / \mathrm{kg}$ of propofol, $2 \mathrm{mg} / \mathrm{kg}$ of fentanyl, and 0.6 $\mathrm{mg} / \mathrm{kg}$ of rocuronium were administered to the patients. After intubation, the respiratory parameters $\left(\mathrm{ETCO}_{2} 30-35 \mathrm{mmHg}\right.$, $50 \% \mathrm{FiO}_{2}$ and air mixture, tidal volume 6-7 Ml/kg, respiratory rate $12-14 /$ minute) were regulated before the patients were connected to the mechanical ventilator support. Anesthesia was maintained using 1\%-2\% sevoflurane and $0.1 \mathrm{mg} / \mathrm{kg}$ rocuronium. Heart rate and rhythm, noninvasive arterial blood pressure, $\mathrm{SpO}_{2}$, and $\mathrm{EtCO}_{2}$ were evaluated at five-minute intervals during the operation. Near the end of the operation, $1 \mathrm{~g}$ of paracetamol was administered to the patient for 15 minutes by IV infusion for postoperative analgesia. Atropine and neostigmine were administered to all patients for decurarization before extubation.

\section{Assessment of Pain}

The patients' levels of pain were evaluated at the $6^{\text {th }}, 24^{\text {th }}$, and $36^{\text {th }}$ hours using the VAS. Pain scores were numbered from 1 to 10 , with 1 indicating no pain and 10 indicating the highest level of pain, requiring significant analgesic intervention.

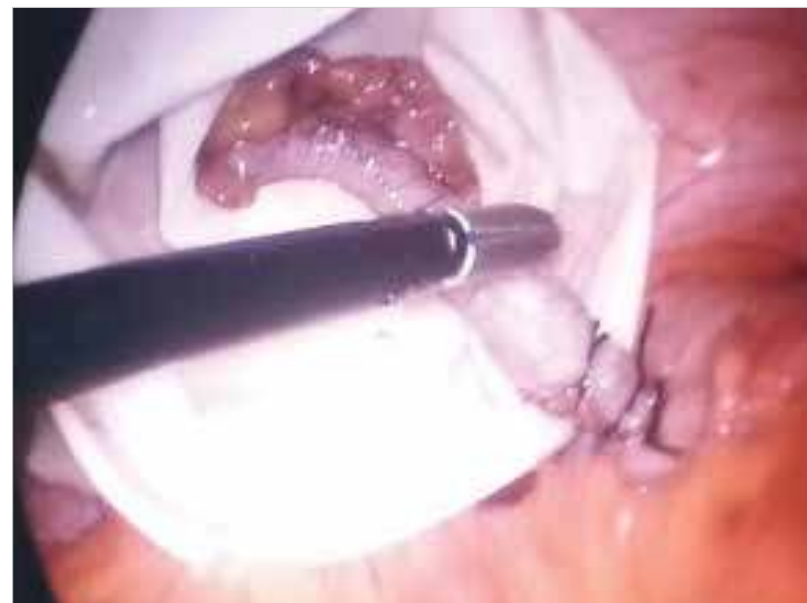

Figure 4. Laparoscopic intracorporeal knotting

\section{Statistical Analysis}

The data were analyzed using the Statistical Package for the Social Sciences version 20.0 for Windows (IBM Corp.; Armonk, NY, USA). The Shapiro-Wilk test was used for the number of units in cases of normal distribution of variables. When measuring the differences between the groups, the Mann-Whitney $U$ test was used when normal distribution was absent. Because the number of units was higher than 20, standardized $z$ values were given for the Mann-Whitney $U$ test. Chi-square analysis was performed to measure the relationship between the nominal variables of the groups examined. To interpret the results, the $\mathrm{p}$-value for the level of statistical significance was set at 0.05 . In cases where $p<0.05$, the variables did not show normal distribution, whereas in cases where $p>0.05$, the variables showed normal distribution. In cases where $2 \times 2$ tables did not have a sufficient volume of expected values in the cells, Fisher's exact test was used. Pearson's chi-square test was applied with the aid of Monte Carlo simulations in the $\mathrm{R} \times \mathrm{C}$ tables. The significance level was set at 0.05 ; if $p<0.05$, the difference was significant, whereas if $p>0.05$, the difference was not significant.

\section{RESULTS}

Of a total of 84 patients, 72 were enrolled in the study; 12 patients were excluded for failing to meet the inclusion criteria. The patients were divided into the following two groups: the LA group (group 1) $(n=36)$ and the OA group (group 2) $(n=36)$. The mean age for the LA group was $29.2( \pm 10)(17-57)$ years, and that for the OA group was $30.1( \pm 11.4)(19-61)$ years $(p=0.142)$. The LA group included 17 females and 19 males, while the OA group included 11 females and 25 males. The body mass indices (BMI) were $24( \pm 3), 4(18.4-32.9) \mathrm{kg} / \mathrm{m}^{2}$ and $24( \pm 3), 4(18.2-31) \mathrm{kg} / \mathrm{m}^{2}$ in group 1 and group 2 , respectively ( $>>0.05)$ (Table 1, 2).

The total follow-up time was 15,586 days; the mean follow-up time was 216 days. In the LA and OA groups, the mean followup times were 277 and 161 days, respectively $(p<0.05)$. LA was performed commonly in the first half of the study. In the LA group, $97.2 \%$ of the cases had loss of appetite, $88.9 \%$ had nausea, $88.9 \%$ had vomiting, $30.6 \%$ had displacement of pain, $100 \%$ had defense, and $86.1 \%$ had rebound. In the OA group, $86.1 \%$ of the cases had loss of appetite, $66.7 \%$ had nausea, $36.1 \%$ had vomiting, $33.3 \%$ had displacement of pain, $100 \%$ had defense, and $94.4 \%$ had rebound. The most common 
Table 1. Comparison of preoperative and postoperative findings between groups

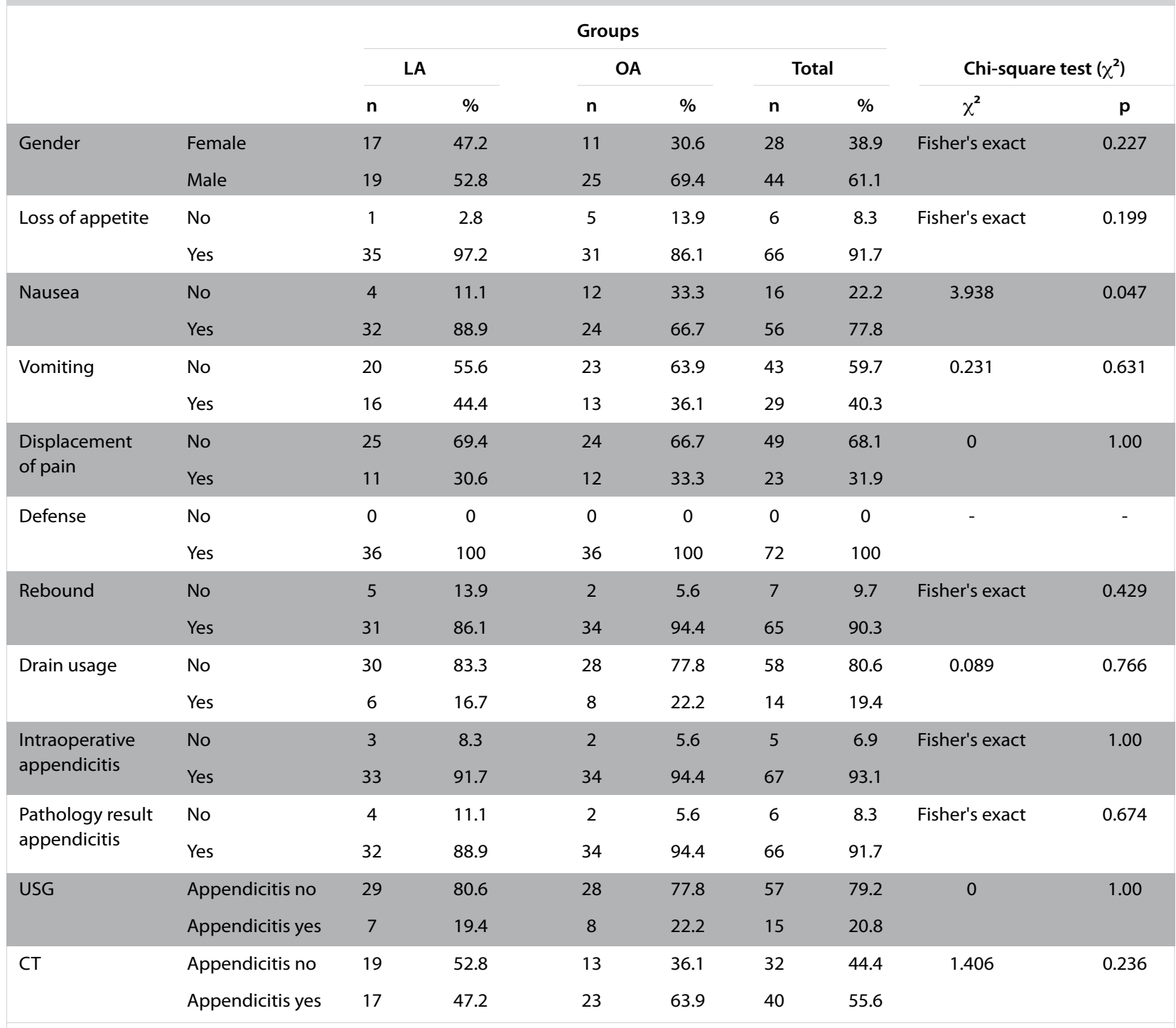

LA: laparoscopic appendectomy; OA: open appendectomy; USG: ultrasonography; CT: computed tomography

symptom was anorexia, while the most frequent finding was defense.

In the $L A$ and $O A$ groups, the mean fever temperatures were $37.5( \pm 0.5){ }^{\circ} \mathrm{C}\left(36.2^{\circ} \mathrm{C}-38.8^{\circ} \mathrm{C}\right)$ and $37.3^{\circ} \mathrm{C}( \pm 0.7)\left(36^{\circ} \mathrm{C}-39^{\circ} \mathrm{C}\right)$, respectively. There were more cases of fever and nausea in the LA group than in the OA group; a statistically significant difference was found between the two groups in terms of nausea and fever ( $p=0.035$ and $p=0.047$, respectively). The durations of primary pain were $37.9( \pm 28)(8-120)$ minutes in the LA group and $45.4( \pm 38)(6-168)$ minutes in the OA group. In the LA group, the preoperative mean white blood cell (WBC) count, neutrophil, lymphocyte, and neutrophil lymphocyte rate (NLR) and platelet distribution width (PDW) were 12300 $( \pm 4445.6)$ (4800 to 20000$) \mathrm{K} / \mathrm{uL}, 9197( \pm 4109)(2970-16800)$ K/uL, 1626.5 ( \pm 755.3$)(158-3200) \mathrm{K} / \mathrm{uL}, 6.9$ ( \pm 3.8$)$ (1.42-18.99) and $14.6( \pm 2.5)(11-19.3)$, respectively. In the OA group, the preoperative mean WBC, neutrophil, lymphocyte, NLR, and PDW were $12051.7( \pm 4698.2)(5000-22100) \mathrm{K} / \mathrm{uL}, 9053.8$ $( \pm 4553.9)(2720-18200) \mathrm{K} / \mathrm{uL}, 1477.2( \pm 33.54)(170-3950) \mathrm{K} /$ uL, 9.2 ( \pm 8.5$)$ (1.37-50.29), and 15 ( \pm 39.06$)$ (11-19.3), respectively. There were no statistically significant differences be- tween the two groups in terms of WBC count, neutrophil, lymphocyte, NLR, or PDW ( $p>0.05$ ). Neither ultrasonography (USG) nor contrast-enhanced computed tomography (CT) was used on any of the patients for diagnosis of acute appendicitis (Table 1-3).

The mean operation time $(76.7( \pm 17.5)$ minutes) of the LA group was higher than that of the OA group $(60.1$ ( \pm 21.8$)$ minutes); a statistically significant difference was found between the two groups with respect to this parameter $(p=0.001)$. A drain was used in patients with gangrenous appendicitis, suspected hemorrhaging, or pelvic fluid (6 patients $(8.3 \%)$ in the LA group and 8 patients $(11.1 \%)$ in the OA group. No statistically significant differences were found between the two groups in terms of the use of drains ( $p>0.05)$ (Table 1, 2).

The mean diameter and length of the appendectomy specimens according to the pathologic examination results were $1( \pm 0.4)$ and $5.9( \pm 2) \mathrm{cm}$, respectively; the diameter and length of the appendectomy specimens in the OA group were $1( \pm 0.4)$ and $5.9( \pm 2) \mathrm{cm}$, respectively. The diameter of the appendectomy specimens in the OA group was longer 
Aziret et al.

Effectiveness of laparoscopic intracorporeal knotting and glove endobag appendectomy

\section{Table 2. Comparison of preoperative and postoperative findings between LA and OA groups}

\begin{tabular}{|c|c|c|c|c|c|c|c|c|c|}
\hline & & & & & & & & Mann & U Test \\
\hline & & $\mathbf{n}$ & Mean & Median & Min & Max & SD & z & p \\
\hline Age & LA & 36 & 29.2 & 26.5 & 17 & 57 & 10.6 & -1.436 & 0.142 \\
\hline & $\mathrm{OA}$ & 36 & 30.1 & 31 & 19 & 61 & 11.4 & & \\
\hline & Total & 72 & 31.7 & 30 & 17 & 61 & 11.2 & & \\
\hline $\mathrm{BMI}\left(\mathrm{kg} / \mathrm{m}^{2}\right)$ & LA & 36 & 24 & 24 & 18.4 & 32.9 & 3.4 & -1.076 & 0.282 \\
\hline & $\mathrm{OA}$ & 36 & 24.4 & 25.2 & 18.2 & 31 & 3 & & \\
\hline & Total & 72 & 24.2 & 24.3 & 18.2 & 32.9 & 3.2 & & \\
\hline Time pain & LA & 36 & 37.9 & 24 & 8 & 120 & 28 & -0.571 & 0.568 \\
\hline started (hours) & OA & 36 & 45.4 & 48 & 6 & 168 & 38 & & \\
\hline & Total & 72 & 41.6 & 24 & 6 & 168 & 33.3 & & \\
\hline Fever $\left({ }^{\circ} \mathrm{C}\right)$ & LA & 35 & 37.5 & 37.5 & 36.2 & 38.8 & 0.5 & -2.105 & 0.035 \\
\hline & OA & 36 & 37.3 & 37.1 & 36 & 39 & 0.7 & & \\
\hline & Total & 71 & 37.4 & 37.3 & 36 & 39 & 0.6 & & \\
\hline Lymphocyte & LA & 36 & 1626.5 & 1605 & 158 & 3200 & 755.3 & -1.2 & 0.23 \\
\hline & OA & 36 & 1477.2 & 1265 & 170 & 3950 & 1015.8 & & \\
\hline & Total & 72 & 1551.8 & 1425 & 158 & 3950 & 891.9 & & \\
\hline NLR & LA & 36 & 6.9 & 6.5 & 1.42 & 18.99 & 3.8 & -1.098 & 0.272 \\
\hline & OA & 36 & 9.2 & 7.5 & 1.37 & 50.29 & 8.5 & & \\
\hline & Total & 72 & 8.1 & 6.9 & 1.37 & 50.29 & 6.6 & & \\
\hline PDW & LA & 36 & 14.6 & 14 & 10.8 & 21.5 & 2.5 & -1.424 & 0.155 \\
\hline & OA & 34 & 15 & 14.9 & 11 & 19.3 & 1.9 & & \\
\hline & Total & 70 & 14.8 & 14.7 & 10.8 & 21.5 & 2.2 & & \\
\hline Operation & LA & 36 & 76.4 & 75 & 45 & 120 & 17.5 & -4.149 & 0.001 \\
\hline time (minutes) & OA & 36 & 60.1 & 55 & 35 & 140 & 21.8 & & \\
\hline & Total & 72 & 68.3 & 63.5 & 35 & 140 & 21.3 & & \\
\hline Pain (6 $6^{\text {th }}$ hour) & LA & 36 & 3.6 & 3 & 2 & 7 & 1.4 & -4.296 & 0.001 \\
\hline & OA & 36 & 5.4 & 5 & 2 & 9 & 1.6 & & \\
\hline & Total & 72 & 4.5 & 5 & 2 & 9 & 1.8 & & \\
\hline Pain ( $24^{\text {th }}$ hour) & LA & 36 & 2.1 & 2 & 0 & 6 & 1.2 & -4.599 & 0.001 \\
\hline & OA & 36 & 3.7 & 3 & 1 & 7 & 1.5 & & \\
\hline & Total & 72 & 2.9 & 3 & 0 & 7 & 1.6 & & \\
\hline Pain ( $36^{\text {th }}$ hour) & LA & 36 & 1.5 & 1 & 0 & 4 & 0.9 & -4.476 & 0.001 \\
\hline & OA & 36 & 2.6 & 2 & 1 & 6 & 1.2 & & \\
\hline & Total & 72 & 2.1 & 2 & 0 & 6 & 1.2 & & \\
\hline Gas output (hours) & LA & 36 & 19.6 & 16 & 6 & 42 & 8.1 & -3.633 & 0.001 \\
\hline & OA & 36 & 28.3 & 30.5 & 10 & 49 & 9.8 & & \\
\hline & Total & 72 & 23.9 & 22 & 6 & 49 & 9.9 & & \\
\hline Diameter of & LA & 36 & 3.2 & 1.5 & 0.4 & 11.5 & 3.5 & -1.333 & 0.182 \\
\hline appendix $(\mathrm{cm})$ & $\mathrm{OA}$ & 36 & 1.2 & 1 & 0.4 & 2.5 & 0.5 & & \\
\hline & Total & 72 & 2.2 & 1 & 0.4 & 11.5 & 2.7 & & \\
\hline Length of & LA & 36 & 5.9 & 5.8 & 2.5 & 10 & 2 & -1.564 & 0.118 \\
\hline appendix (cm) & OA & 36 & 6.6 & 6.3 & 3.5 & 10 & 1.9 & & \\
\hline & Total & 72 & 6.2 & 6 & 2.5 & 10 & 1.9 & & \\
\hline Return to normal & LA & 36 & 3.1 & 3 & 2 & 8 & 1.3 & -1.146 & 0.252 \\
\hline activity (days) & OA & 36 & 3.3 & 3 & 1 & 6 & 1.1 & & \\
\hline & Total & 72 & 3.2 & 3 & 1 & 8 & 1.2 & & \\
\hline Beginning of & LA & 36 & 10.8 & 10 & 1 & 25 & 4.6 & -3.443 & 0.001 \\
\hline work (days) & OA & 36 & 15.5 & 15 & 6 & 35 & 6.1 & & \\
\hline & Total & 72 & 13.2 & 12 & 1 & 35 & 5.8 & & \\
\hline Follow-up period & LA & 36 & 277 & 211 & 65 & 424 & 67 & -2.405 & 0.001 \\
\hline (days) & OA & 36 & 161 & 159 & 15 & 424 & 86 & & \\
\hline & Total & 72 & 216 & 212 & 15 & 424 & 85 & & \\
\hline
\end{tabular}

LA: laparoscopic appendectomy; OA: open appendectomy; BMl: body mass index; PDW: platelet distribution width; NLR: neutrophil lymphocyte rate; SD: standard deviation; Min: minimum; Max: maximum 
Table 3. Comparison of preoperative and postoperative results between LA and OA

\begin{tabular}{|c|c|c|c|c|c|c|c|c|c|}
\hline & & \multicolumn{6}{|c|}{ Group } & \multicolumn{2}{|c|}{ Independent T-Test } \\
\hline & & $\mathrm{n}$ & Mean & Median & Min & $\operatorname{Max}$ & SD & $\mathbf{t}$ & p \\
\hline \multirow[t]{3}{*}{ WBC } & LA & 36 & 12300 & 12550 & 4800 & 20000 & 4445.6 & 0.23 & 0.818 \\
\hline & $\mathrm{OA}$ & 36 & 12051.7 & 11600 & 5000 & 22100 & 4698.2 & & \\
\hline & Total & 72 & 12175.8 & 11850 & 4800 & 22100 & 4543 & & \\
\hline \multirow[t]{3}{*}{ Neutrophil } & LA & 36 & 9197.9 & 9825 & 2970 & 16800 & 4109 & 0.141 & 0.888 \\
\hline & $\mathrm{OA}$ & 36 & 9053.8 & 8065 & 2720 & 18200 & 4553.9 & & \\
\hline & Total & 72 & 9125.8 & 8680 & 2720 & 18200 & 4307.1 & & \\
\hline \multirow[t]{3}{*}{ Stool output (hours) } & LA & 36 & 41 & 38.5 & 20 & 78 & 14.9 & -5.782 & 0.001 \\
\hline & $\mathrm{OA}$ & 36 & 64.2 & 66 & 24 & 96 & 19 & & \\
\hline & Total & 72 & 52.6 & 50 & 20 & 96 & 20.6 & & \\
\hline
\end{tabular}

LA: laparoscopic appendectomy; OA: open appendectomy; WBC: white blood cell; SD: standard deviation; Min: minimum; Max: maximum

than that in the LA group ( $p=0.031$ ) (Table 2). In a total of five patients (three LA and two OA), the appearance of appendicitis was not found macroscopically, and we were unable to detect any pathology that could explain this clinical presentation. However, because we were unable to conduct microscopic evaluations, we still performed appendectomies on these patients. Vermicular appendix was found in four of these five patients, and our negative appendectomy rate was $8.3 \%(6 / 72)$ (Table 1$)$.

The mean VAS pain scores were found to be significantly lower in the LA patients; the mean $6^{\text {th }}, 24^{\text {th }}$, and $36^{\text {th }}$ hour pain scores of the patients in this group were $3.6( \pm 1.4), 2.1( \pm 1.2)$, and $1.5( \pm 0.9)$, respectively, while those in the OA group were $5.4( \pm 1.6), 3.7( \pm 1.5)$ and $2.6( \pm 1.2)$, respectively. A statistically significant difference was observed between the two groups in terms of pain scores $(p=0.001)$ (Table 2$)$. The timing of gas and stool outputs was determined during postoperative follow-up; it was found that gas and stool output occurred earlier in the LA group, which had mean gas and stool output times of $19.6( \pm 8.1)$ hours and $41( \pm 14.9)$ hours, respectively. In the OA group, the mean gas and stool output times were $28.3( \pm 45.4)$ hours and $64.2( \pm 19)$ hours, respectively. A statistically significant difference was observed between the LA and OA groups in terms of gas and stool output times $(p=0.001)$ (Table 2, 3). The hospitalization times were also significantly longer in the OA group. In the LA and OA groups, the mean hospitalization times were $3.1( \pm 1.3)$ days and $3.3( \pm 1.1)$ days, respectively. In the LA group, the mean RTNA was shorter than that in the OA group; a statistically significant difference was detected between the two groups with respect to this parameter $(p=0.001)$ (Table 2$)$.

There were no cases of mortality in the study. Surgical-site infection was observed in a total of six patients among the two groups, occurring in five patients (13.9\%) in the OA group and in one patient (1.3\%) in the LA group. In these patients, wound cultures were taken, prophylactic antibiotics were started, and surgical-site care was administered until complete healing occurred. In a total of two patients (2.7\%), incisional hernia was observed in the left trocar-site on the $3^{\text {rd }}$ and $5^{\text {th }}$ postoperative days. These patients were taken to the operating room, where the trocar-site incisional hernias were primer-repaired under sedoanalgesia. Trocar-site incisional hernias were found in these two patients only.

Among both groups, a major complication was observed in a total of one patient in the OA group. A partial pulmonary embolism was observed in one patient, who was admitted to the emergency room with breathlessness after the postoperative $15^{\text {th }}$ day. The 46-year-old female patient presented with weakness but did not have any comorbidities. Findings from her pathological specimen revealed gangrenous appendicitis. The patient was hospitalized at the pulmonary disease clinic, where she was started on anticoagulant and bronchodilator therapy. She was discharged uneventfully with low-molecular-weight heparin. No incidences of intraabdominal abscess, hemorrhage, or appendectomy stump leakage were found in either the LA or the OA group (Table 4).

\section{DISCUSSION}

Acute appendicitis is the most common cause of acute abdomen, and appendectomies are the most commonly performed emergency abdominal surgery in adults (1). The appendectomy risk for males and females during their lifetime are $12 \%$ and $23 \%$, respectively, and approximately $7 \%$ of all people will undergo an appendectomy for acute appendicitis at some point in their lifetime $(1,2)$. The annual appendectomy rate for acute appendicitis is $10 / 10000(2,3)$.

Open appendectomy has remained the gold standard for more than a century since McBurney's incision was described in 1894 (4). After Semm et al. (5) performed the first LA, the path for a much wider application of minimally invasive surgery was opened. LA was revealed to be an effective procedure that could be performed in a short time. Over the years, many studies have compared OA and LA (6-10). In a prospective randomized study conducted by Hansen et al. (6) on the effectiveness of LA, it was found that LA resulted in less wound infection, decreased analgesic need, and earlier RTNA but had a longer operation time. In a meta-analysis conducted by Temple et al. (7), it was shown that LA had an early RTNA but had longer operation and hospital stay times. In addition, Korndorffer (8) and Reiertsen (9) reported lower misdiagnosis rates, decreased analgesic need, and less wound infection with LA. However, LA does have some drawbacks, such as in- 


\begin{tabular}{|c|c|c|c|c|c|c|c|c|c|}
\hline & & \multicolumn{6}{|c|}{ Groups } & & \\
\hline & & \multicolumn{2}{|c|}{ LA } & \multicolumn{2}{|c|}{$\mathrm{OA}$} & \multicolumn{2}{|c|}{ Total } & \multicolumn{2}{|c|}{ Chi-square test $\left(\chi^{2}\right)$} \\
\hline & & $\mathrm{n}$ & $\%$ & $n$ & $\%$ & $\mathbf{n}$ & $\%$ & $\chi^{2}$ & $p$ \\
\hline \multirow[t]{2}{*}{ Surgical-site infection } & No & 35 & 97.2 & 31 & 86.1 & 66 & 91.7 & Fisher's exact & 0.199 \\
\hline & Yes & 1 & 2.8 & 5 & 13.9 & 6 & 8.3 & & \\
\hline \multirow[t]{2}{*}{ Incisional hernia } & No & 34 & 94.4 & 36 & 100 & 70 & 97.2 & Fisher's exact & 0.493 \\
\hline & Yes & 2 & 5.6 & 0 & 0 & 2 & 2.8 & & \\
\hline \multirow[t]{2}{*}{ Stump leakage } & No & 36 & 100 & 36 & 100 & 72 & 100 & - & - \\
\hline & Yes & 0 & 0 & 0 & 0 & 0 & 0 & & \\
\hline \multirow{2}{*}{$\begin{array}{l}\text { Partial pulmonary } \\
\text { embolism }\end{array}$} & No & 36 & 100 & 35 & 97.2 & 71 & 98.6 & Fisher's exact & 1 \\
\hline & Yes & 0 & 0 & 1 & 2.8 & 1 & 1.4 & & \\
\hline
\end{tabular}

creased rate of intraabdominal abscess and the requirement for costly instruments, such as endostaplers, endoclips, and endoloops (10-15). In the present study, we aimed to decrease the costs associated with LA by using intracorporeal knotting and glove-endoloop. In addition, we sought to compare LA and $\mathrm{OA}$ in terms of pre/intra/postoperative technique, time of return of gastrointestinal functions, and complications.

An endostapler, extracorporeal sliding knots, endoloops, endoclips, and endobags are usually used to remove the appendix during LA. These devices are costly and are not always accessible; however, the operation cannot be performed without the use of these instruments. In a prospective study on LA conducted by Hanssen (11), the appendix stump was ligated with polymeric clips (Hem-o-lok); this technique was found to be a feasible, safe, and economic alternative to ligation of the appendicular stump during LA. Beldi et al. (12) used a stapler in $60.5 \%$ of patients and an endoloop in $39.5 \%$ of patients for appendix stump ligation in their study; they reported surgicalsite infection rates of $0.7 \%$ and $1.7 \%$ in the stapler group and endoloop group, respectively. In studies conducted by Moreno (13) and by Delibegović et al. (14), for Gea extracorporeal knotting, endoloops and Hem-o-lok plastic clips were used for the appendix stump ligation. Delibegović and Matović (14) reported that the operation time was $47.1( \pm 6.7)$ minutes in the endoloop group and $38.7( \pm 5.0)$ minutes in the non-absorbable Hem-o-lok clip group. In a study conducted by Ay (15) on the effects of the intracorporeal knotting technique for appendix stump ligation, they found that the median operation time was (range 26 to 100) minutes. Furthermore, in a study with 141 cases conducted by Katsuno et al. (16) on the use of a laparoscopic stapler or $2 / 0$ or $0 / 0$ PolySorb for appendix stump ligation in complicated appendicitis, it was found that the mean operation time was 116.7 minutes and the mean duration of hospital stay was 8.9 days. In the present study, the appendix stump was ligated with $2 / 0$ non-absorbable silk, and we removed the appendectomy specimen from the abdominal cavity with an intraoperatively prepared glove endobag. As a result, the operation cost was reduced and LA could be easily and effectively performed with intracorporeal knotting and glove endobag. Despite the increased operation time in the LA group compared to the OA group, our operation times were found to
Surgical-site infection can be seen after appendectomy. Deep surgical-site infection is more common in patients who undergo LA than in patients who undergo OA. In a study on LA conducted by Ay (15), 10.7\% surgical-site infection and 7.1\% small bowel obstruction rates were reported. In a study on LA conducted by Katsuno (16), 6.4\% surgical-site infection, $4.3 \%$ intraabdominal abscess, and $2.1 \%$ small bowel obstruction rates were reported. In our study, the surgical-site infection rates were found to be $13.9 \%$ and $2.8 \%$ in the $\mathrm{OA}$ and LA groups, respectively. There were no statistically significant differences between the groups in terms of surgical-site infection. However, in one patient, a partial pulmonary embolism was observed. The patient was discharged uneventfully after undergoing treatment and follow-up (Table 3).

The length of hospital stay and RTNA are important indicators of patient recovery; many studies have shown that the length of hospital stay and RTNA are shorter in patients who underwent LA than in those who underwent OA (17-20). In a study on LA conducted by Shaikh et al. (17), the hospital stay time and RTNA were found to be 1.7 and 12.6 days, respectively. Additionally, in a meta-analysis consisting of prospective randomized studies conducted by Li et al. (18), it was reported that the length of hospital stay was less than 0.6 days and the RTNA was earlier than 4.5 days in patients who underwent LA. In our study, because the patients generally lived far from the center, the length of hospital stay was longer than that found in the literature. We observed that the LA group had shorter hospital stay times and earlier RTNA. A statistically significant difference was found between the groups in terms of RTNA $(p=0.001)$ (Table 2).

Postoperative pain is an important problem following surgery and is directly related to quality of life. Postoperative pain levels and need for analgesics can be determined through VAS scores (18). Many studies have reported that patients who underwent LA had less postoperative pain and decreased need for analgesics (18-20). In a study on LA conducted by Cipe (19) involving 241 cases, it was found that the mean VAS scores were 4 (versus 4.6 in OA) and 2.9 (versus 3.4 in OA) at the $4^{\text {th }}$ and $24^{\text {th }}$ hours, respectively. Similar to the results found in the literature, we found that the VAS scores in the LA group were lower and that the OA group had greater postoperative analgesic requirements. The 
mean VAS scores of the LA group in our study were 3.6 (versus 5.4 in $\mathrm{OA}$ ), 2.1 (versus 3.7 in $\mathrm{OA}$ ), and 1.5 (versus 2.6 in $\mathrm{OA}$ ) at the $4^{\text {th }}, 24^{\text {th }}$, and $36^{\text {th }}$ hours, respectively. In addition, a statistically significant difference was found between the groups in terms of postoperative pain ( $p=0.001$ ) (Table 2 ).

Laparotomy and anesthesia can inhibit intestinal motility. The paralytic period occurs even in cases of minor surgery and usually ends spontaneously within 0 to 24 hours in the small intestine, within 24 to 48 hours in the stomach, and within 48 to 72 hours in the colon after major abdominal surgery (21). The etiopathogenesis is not clear for decreased motility; however, it is thought to be related to the anesthetic agents used, manipulation of the intestine, increased sympathetic tone, and administration of opioids after surgery (22). However, some simple preventive methods can be used, such as intestinal manipulation limitations and a meticulous approach to tissue by the surgeon during the surgery (23). The PubMed database was searched to discover the relationship between gas-stool outputs and LA. Unfortunately, supporting clinical studies could not be accessed. In our study, the LA group had shorter gas-stool output times; the mean gas and stool output times for LA were 19.6 hours (versus 28.3 hours in OA) and 41 hours (versus 64.2 in OA), respectively. A statistically significant difference was found between the groups in terms of postoperative pain ( $p=0.001$ ) (Table 2,3 ). We believe that these results may be associated with less manual manipulation, early feeding, and decreased need for analgesics.

There were some limitations to our study. First, our patients generally resided in rural areas. Secondly, the average altitude of the region where the study was conducted is 1768 meters, and in winter, the temperature sometimes decreases to -39 ${ }^{\circ} \mathrm{C}$; the region is covered with snow for more than 120 days. These geographical conditions may have affected the patients hospital visits and discharge times. Finally, in our study, because USG and CT could not be performed on every patient, comparisons were limited.

\section{CONCLUSION}

In the present study, we found less postoperative pain, decreased need for analgesics, and earlier gas-stool outputs, discharge rates, and RTNA in patients who underwent LA compared to those who underwent OA. In addition, through the use of laparoscopic intracorporeal knotting and glove endobag, the costs associated with the LA procedure can be reduced. As a result, we believe that $L A$ is an effective surgical method for appendectomy.

Ethics Committee Approval: Ethics committee approval was received for this study from the ethic committee of Health Science University Adana Training and Research Hospital.

Informed Consent: Written informed consent was obtained from patients who participated in this study.

Peer-review: Externally peer-reviewed.

Author Contributions: Concept - M.A., O.I.; Design - S.Ç.; Supervision - H.E., H.B.; Materials - O.D.; Data Collection and/or Processing - S..K.; Analysis and/or Interpretation - M.A., A.C.Y.; Literature Search - A.C.Y.; Writing Manuscript - M.A.; Critical Reviews - O.I.
Conflict of Interest: No conflict of interest was declared by the authors.

Financial Disclosure: The authors declared that this study has received no financial support.

\section{REFERENCES}

1. Addiss DG, Shaffer N, Fowler BS, Tauxe RV. The epidemiology of appendicitis and appendectomy in the United States. Am J Epidemiol 1990; 132: 910-925. [CrossRef]

2. Flum DR, Morris A, Koepsell T, Dellinger EP. Has misdiagnosis of appendicitis decreased over time? A population-based analysis. JAMA 2001; 286: 1748-1753. [CrossRef]

3. Brunicardi FC, Andersen DK, Billiar TR, Dunn DL, Hunter JG, Matthews JB, Pollock RE. The Appendix. In Schwart'z principles of surgery. 9nd ed. 2010; p.1074-1078.

4. McBurney IV C. The incision made in the abdominal wall in cases of appendicitis, with a description of a new method of operating. Ann Surg 1894; 20: 38-43. [CrossRef]

5. Semm K. Endoscopic appendectomy. Endoscopy 1983; 15: 59-64. [CrossRef]

6. Hansen JB, Smithers BM, Schache D, Wall DR, Miller BJ, Menzies BL. Laparoscopic versus open appendectomy: prospective randomized trial. World J Surg 1996; 20: 17-20. [CrossRef]

7. Temple LK, Litwin DE, McLeod RS. A meta-analysis of laparoscopic versus open appendectomy in patients suspected of having acute appendicitis. Can J Surg 1999; 42: 377-383.

8. Korndorffer Jr, Fellinger E, Reed W. SAGES guideline for laparo-scopic appendectomy. Surg Endosc 2010; 24: 757-761. [CrossRef]

9. Reiertsen O, Larsen S, Trondsen E, Edwin B, Faerden AE, Rosseland AR. Randomized controlled trial with sequential design of lap $\neg$ aroscopic versus conventional appendectomy. Br J Surg 1997; 84: 842-847. [CrossRef]

10. Heikkinen TJ, Haukipura K, Hulkko A. Cost-effective appendectomy: open or laparoscopic? A prospective, randomized study. Surg Endosc 1998; 12: 1204-1208. [CrossRef]

11. Hanssen A, Plotnikov S, Dubois R. Laparoscopic appendectomy using a polymeric clip to close the appendicular stump. JSLS 2007; 11: 59-62.

12. Beldi G, Vorburger SA, Bruegger LE, Kocher T, Inderbitzin D, Candinas $D$. Analysis of stapling versus endoloops in appendiceal stump closure. Br J Surg 2006; 93: 1390-1393. [CrossRef]

13. Moreno M, Magos FJ, Arcovedo R, Olachea P, Palacios JA, Salazar $A$, et al. Comparison of the perfor-mance of the Gea extracorporeal knot with the Roeder extracorporeal knot and the classical knot. Surg Endosc 2004; 18: 157-160. [CrossRef]

14. Delibegović S, Matović E. Hem-o-lok plastic clips in securing of the base of the appendix during laparoscopic appendectomy. Surg Endosc 2009; 23: 2851-2854. [CrossRef]

15. Ay N, Dinç B, Alp V, Kaya Ş, Sevük U. Comparison of outcomes of laparoscopic intracorporeal knotting technique in patients with complicated and noncomplicated acute appendicitis. Ther Clin Risk Manag 2015; 11: 1213-1216. [CrossRef]

16. Katsuno G, Nagakari K, Yoshikawa S, Sugiyama K, Fukunaga M. Laparoscopic appendectomy for complicated appendicitis: a comparison with open appendectomy. World J Surg 2009; 33: 208-214.[CrossRef]

17. Shaikh AR, Sangrasi AK, Shaikh GA. Clinical outcomes of laparoscopic versus open appendectomy. JSLS. 2009; 13: 574-580. [CrossRef]

18. Li X, Zhang J, Sang L, Zhang W, Chu Z, Li X, et al. Laparoscopic versus conventional appendectomy - a metaanalysis of randomized controlled trials. BMC Gastroenterol 2010; 10: 129. [CrossRef] 
Aziret et al.

Effectiveness of laparoscopic intracorporeal knotting and glove endobag appendectomy

19. Cipe G, Idiz O, Hasbahceci M, Bozkurt S, Kadioglu H, Coskun H, et al. Laparoscopic versus open appendectomy: where are we now? Chirurgia (Bucur) 2014; 109: 518-22.

20. Sauerland S, Jaschinski T, Neugebauer EA. Laparoscopic versus open surgery for suspected appendicitis. Cochrane Database Syst Rev 2010; 10: CD001546. [CrossRef]

21. Nivatvongs $\mathrm{S}$. Complications of anorectal and colorectal operations. In: Gordon PH, Nivatvongs S. Principles and practice of sur- gery for colon, rectum, and anus. Informa Healthcare, New York 2007. p. 1165-1189.

22. Ogilvy AJ, Smith G. The gastrointestinal tract after anesthesia. Eur J Anesthesiol 1995; 10: 35-42

23. Pickleman J, Lee RM. The management of patients with suspected early postoeprative small bowel obstruction. Ann Surg 1989; 210: 216-219. [CrossRef] 